\title{
PEMODELAN NILAI KURS TERHADAP HARGA SAHAM PADA DATA LONGITUDINAL MENGGUNAKAN REGRESI NONPARAMETRIK SPLINE TRUNCATED
}

\author{
Milatus Sholikha $^{1 \S}$, Made Susilawati ${ }^{2}$, I Gusti Ayu Made Srinadi ${ }^{3}$ \\ ${ }^{1}$ Program Studi Matematika, Fakultas MIPA - Universitas Udayana [Email: milatussholikha@gmail.com] \\ ${ }^{2}$ Program Studi Matematika, Fakultas MIPA - Universitas Udayana [Email: mdsusilawati@unud.ac.id] \\ ${ }^{3}$ Program Studi Matematika, Fakultas MIPA - Universitas Udayana [Email: srinadi@unud.ac.id] \\ ${ }^{\S}$ Corresponding Author
}

\begin{abstract}
The purpose of this study was to obtain the models between currency value and stocks in longitudinal data. The models were obtained by using nonparametric truncated spline regression. The data consisted of stocks from three companies namely PT. Mandom Indonesia, PT. Unilever Indonesia and PT. Akasha Wira Internasional and currency value of AUD to IDR. The data were splitted into two sub samples which were "in sample" data from January 2013-December 2017 that were used to generate the models and "out sample" data from January 2016-December 2018 to validate the models, MAPE was used as measurement in validation. This resulted in three distinctive models which were model with $3^{\text {nd }}$ order and 3 knots for PT. Mandom Indonesia and PT. Unilever Indonesia, model with $2^{\text {nd }}$ order and 4 knots for PT. Akasha Wira Internasional stock, all with there own respective knot points and MAPE value of $9.62 \%, 15.61 \%$ and $48.8 \%$ sub sequently.
\end{abstract}

Keywords: stocks, longitudinal data, nonparametric truncated spline regression, GCV

\section{PENDAHULUAN}

Perkembangan ekonomi pada suatu negara menjadi salah satu perhatian pemerintah untuk membawa bangsanya kepada kehidupan yang lebih baik, perkembangan ekonomi dapat terlihat dari indikator pasar modal pada negara tersebut. Menurut Muklis (2016) keberadaan pasar modal di Indonesia merupakan salah satu faktor penting dalam pembangunan perekono-mian nasional, terbukti telah banyak industri dan perusahaan yang menggunakan institusi ini sebagai media untuk menyerap investasi dan memperkuat posisi keuangannya. Salah satu investasi yang ditawarkan investor di pasar modal adalah saham. Saham dapat didefini-sikan sebagai tanda kepemilikan seseorang atau badan dalam suatu perusahaan maupun perseroan terbatas.

Faktor-faktor yang memengaruhi pergerakan harga saham, yaitu faktor internal dan faktor eksternal. Faktor internal merupakan faktor yang berkaitan langsung dengan kinerja atau kondisi suatu perusahaan yang dilihat dari data-data laporan keuangan selama perusahaan melakukan kegiatan operasinya. Faktor eksternal merupakan faktor yang tidak berkaitan langsung dengan kondisi perusahaan, seperti tingkat suku bunga, tingkat inflasi, kurs valuta asing dan sebagainya (Agustina dan Sumartio, 2014).Data harga saham dari beberapa perusa-haan yang diamati dalam kurun waktu tertentu termasuk data longitudinal atau sering disebut dengan data panel. Data longitudinal merupa-kan data yang dihimpun dari suatu pengama-tan atau pengukuran atas sejumlah subjek yang dilakukan berulang dari waktu ke waktu.

Tujuan penelitian ini adalah memodelkan nilai kurs terhadap saham pada data longitudinal dengan menggunakan metode regresi nonparametrik spline truncated. Secara umum data longitudinal dapat ditulis sebagai berikut:

$$
\left(Y_{i j}, X_{i j}\right) ; i=1, \ldots ., n, j=1, \ldots ., m
$$

$n$ menyatakan banyaknya subjek dan $m$ menyatakan banyak amatan tiap subjek, dengan $Y_{i j}$ menyatakan variabel respon untuk subjek ke- $i$ dan waktu ke-j dan $X_{i j}$ menyatakan variabel prediktor untuk subjek ke- $i$ dan waktu ke- $j$.

Data harga saham cenderung fluktuatif dan tidak berdistribusi normal sehingga data dapat 
diestimasi menggunakan pendekatan regresi nonparametrik.

Secara umum model regresi nonparametrik sebagai berikut (Eubank, 1999):

$$
Y_{i}=f\left(x_{i}\right)+\varepsilon_{i}, i=1,2, \ldots, n
$$

$Y_{i}$ menyatakan variabel respon pada subyek ke- $i, f\left(x_{i}\right)$ menyatakan variabel prediktor yang tidak diketahui kurva atau polanya, $x_{i}$ menyatakan variabel prediktor pada subyek ke$i$, dan $\varepsilon_{i}$ merupakan error pengukuran pada subjek ke-i. Model regresi nonparametrik untuk data longitudinal adalah sebagai berikut (Suparti et al, 2017):

$$
\begin{aligned}
Y_{i j}=f\left(x_{i j}\right)+\varepsilon_{i j}, i & =1,2, \ldots, n ; \\
j & =1,2, \ldots, m
\end{aligned}
$$

$Y_{i j}$ menyatakan variabel respon pada subyek ke$i$ waktu ke- $j, f\left(x_{i j}\right)$ menyatakan variabel prediktor yang tidak diketahui kurva atau polanya, $x_{i j}$ menyatakan variabel prediktor pada subyek ke- $i$ waktu ke- $j$, dan $\varepsilon_{i j}$ merupakan error pengukuran pada subjek ke-i waktu ke-j.

Salah satu estimator pada regresi nonparametrik adalah spline. Pendekatan regresi nonparametrik menggunakan metode spline cenderung mencari sendiri estimasi data dari pola yang terbentuk (Budiantara, 2011). Beberapa hal yang perlu diperhatikan dalam membentuk regresi spline adalah menentukan orde model, banyaknya titik knot, serta lokasi knot tersebut (Toruan, 2018). Secara umum persamaan fungsi regresi nonparametrik spline truncated berorde $k$ dengan titik knot $K=$ $\left\{\tau_{1}, \tau_{2}, \ldots, \tau_{K}\right\}$ misalkan terdapat data longitudinal dengan $i=1,2, \ldots, n ; j=$ $1,2, \ldots, m$ sebagai berikut (Suparti et al, 2017):

$$
f\left(x_{i j}\right)=\sum_{p=0}^{k} \alpha_{p_{i}} x_{i j}^{p}+\sum_{r=1}^{K} \beta_{r_{i}}\left(x_{i j}-\tau_{r_{i}}\right)_{+}^{k}
$$

$k, \alpha_{0}, \alpha_{1}, \alpha_{2}, \ldots, \alpha_{k}, \beta_{1}, \beta_{2}, \ldots, \beta_{K}$

adalah parameter-parameter yang tidak diketahui, dan $\left\{\tau_{r_{i}} ; \tau_{r_{1}}<\tau_{r_{2}}<\cdots<\tau_{r_{K}}\right\} \quad$ merupakan himpunan titik knot ke- $r$ dari subjek ke- $i$, serta $\left(x_{i j}-\tau_{i s}\right)_{+}^{k-1}$ merupakan fungsi truncated yang dapat dijabarkan sebagai berikut:

$$
\left(x_{i j}-\tau_{i s}\right)_{+}^{k}= \begin{cases}\left(x_{i j}-\tau_{r_{i}}\right)^{k} ; & x_{i j} \geq \tau_{r_{i}} \\ 0 & ; \quad x_{i j}<\tau_{r_{i}}\end{cases}
$$

Sehingga persamaan regresi nonparametrik untuk data longitudinal dapat disajikan sebagai berikut:
$Y_{n m}=\sum_{p=0}^{k} \alpha_{p_{n}} x_{n m}^{p}+\sum_{r=1}^{K} \beta_{r_{n}}\left(x_{n m}-\tau_{r_{n}}\right)_{+}^{k}+\varepsilon_{n m}$

Dengan demikian persamaan 5 dapat disajikan dalam bentuk matriks seperti pada persamaan 6 berikut:

$$
\mathbf{Y}=\mathbf{X B}+\boldsymbol{\varepsilon}
$$

dimana

$$
\begin{aligned}
& \mathbf{Y}=\left[\begin{array}{c}
\mathbf{Y}_{1} \\
\mathbf{Y}_{2} \\
\vdots \\
\mathbf{Y}_{\mathbf{n}}
\end{array}\right] ; \quad \mathbf{X}=\left[\begin{array}{cccc}
\mathbf{X}_{1}[\boldsymbol{\tau}] & 0 & 0 & 0 \\
0 & \mathbf{X}_{2}[\boldsymbol{\tau}] & 0 & 0 \\
0 & 0 & \ddots & 0 \\
0 & 0 & 0 & \mathbf{X}_{\mathrm{n}}[\boldsymbol{\tau}]
\end{array}\right] ; \\
& \mathbf{B}=\left[\begin{array}{c}
\mathbf{B}_{1} \\
\mathbf{B}_{2} \\
\vdots \\
\mathbf{B}_{n}
\end{array}\right] ; \quad \boldsymbol{\varepsilon}=\left[\begin{array}{c}
\varepsilon_{1} \\
\varepsilon_{2} \\
\vdots \\
\varepsilon_{n}
\end{array}\right]
\end{aligned}
$$

Dengan menggunakan metode Ordinary Least Square (OLS), diperoleh estimator untuk parameter $\beta$ sebagai berikut:

$$
\widehat{\boldsymbol{\beta}}=\left(\mathbf{X}^{\mathbf{T}} \mathbf{X}\right)^{-\mathbf{1}} \mathbf{X}^{\mathbf{T}} \mathbf{Y}
$$

Fungsi estimator dari $f(x)$ untuk regresi nonparametrik spline dengan titik knot $\mathrm{K}=$ $\left\{\tau_{1}, \tau_{2}, \ldots, \tau_{K}\right\}$ sebagai berikut:

$$
\hat{f}_{K}(x)=X_{K} \hat{\beta}_{K}=X_{K}\left(X_{K}^{T} X_{K}\right)^{-1} X_{K}^{T} Y
$$

Sehingga dapat ditulis:

$$
\hat{Y}_{K}=X_{K}\left(X_{K}^{T} X_{K}\right)^{-1} X_{K}^{T} Y=A_{K} Y
$$

$\hat{Y}_{K}=\left(\hat{Y}_{1}, \ldots, \hat{Y}_{n}\right)^{T}$, dengan $\hat{Y}_{K}=\hat{f}_{K}(x)$ dan

$$
A_{K}=X_{K}\left(X_{K}^{T} X_{K}\right)^{-1} X_{K}^{T}
$$

Pemilihan titik knot optimal sangat penting dalam regresi nonparametrik, karena estimator spline terbaik diperoleh dengan menggunakan titik knot optimal. Titik knot merupakan titik perpaduan bersama dimana terdapat perubahan pola perilaku fungsi atau kurva. Titik knot optimal dapat ditentukan dengan menggunakan nilai Generalized Cross Validation (GCV) (Litawati dan Budiantara, 2013).

Pemilihan menggunakan nilai GCV dapat didefinisikan sebagai berikut:

$$
\operatorname{GCV}(K)=\frac{m^{-1} \sum_{j=1}^{m}\left[y_{i j}-\hat{y}_{i j}\right]^{2}}{\left\{1-\operatorname{tr}\left(A_{K}\right) / m\right\}^{2}}
$$

$G C V(K)$ merupakan vektor yang memuat nilai GCV dari $K$ yang merupakan titik-titik knot, $m$ adalah banyaknya pengamatan, $y_{i j}$ menyatakan variabel respon untuk subjek ke- $i$ dan waktu ke$j, A_{K}=X_{K}\left(X_{K}^{T} X_{K}\right)^{-1} X_{K}^{T}$.

Salah satu cara untuk mengetahui ketepatan peramalan sebuah model dapat menggunakan nilai Mean Absolute Percentage Error (MAPE). 
Nilai MAPE dapat memberikan petunjuk tentang seberapa besar rata-rata kesalahan absolut peramalan. Rumus untuk menghitung nilai MAPE sebagai berikut:

$$
M A P E=\frac{\sum_{i=1}^{n} \sum_{j=1}^{n_{i}}\left|\left(\frac{y_{i j}-\hat{y}_{i j}}{y_{i j}}\right) \times 100 \%\right|}{\sum_{i=1}^{n} n_{i}}
$$

Jika nilai MAPE yang diperoleh semakin kecil maka semakin akurat peramalan sebuah model. Interpretasi dari nilai MAPE yang dihasilkan (Chen et al, 2007):

1. $M A P E<10 \%$ : peramalan tersebut sangat akurat

2. $10 \% \leq M A P E<20 \% \quad$ : peramalan tersebut baik

3. $20 \% \leq M A P E<50 \%$ : peramalan tersebut cukup

4. $M A P E \geq 50 \%$ tersebut tidak akurat

\section{METODE PENELITIAN}

\section{A. Jenis dan Sumber Data}

Data yang digunakan dalam penelitian ini adalah data sekunder yang diperoleh dari website resmi Bank Indonesia untuk data nilai kurs tengah AUD terhadap rupiah dari Januari 2013-Desember 2017, sedangkan data harga saham bulanan periode Januari 2013-Desember 2017 diperoleh dari website yahoo finance. Data out sample yang digunakan dalam penelitian ini adalah data saham bulanan periode Januari 2016-Desember 2018.

\section{B. Teknik Analisis Data}

Tahapan analisis dalam penelitian ini adalah: (1) Membuat scatterplot untuk variabel respon dengan variabel prediktor pada masing-masing perusahaan. Menentukan titik knot optimal menggunakan nilai Generalized Cross Validation (GCV) minimum pada setiap perusahaan. Membentuk model spline terbaik berdasarkan titik knot optimal pada setiap perusahaan.

(4) Menghitung akurasi dugaan model terbaik menggunakan nilai MAPE pada data out sample.

\section{HASIL DAN PEMBAHASAN}

\section{A. Scatterplot Pada Setiap Perusahaan}

Membuat scatterplot bertujuan untuk mengetahui apakah kurva regresi yang diidentifikasikan melalui plot-plot membentuk suatu pola tertentu atau tidak.

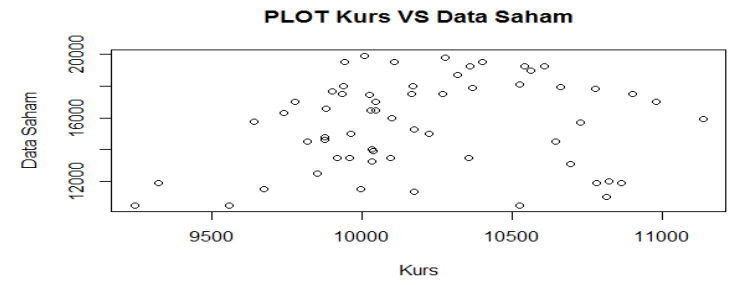

Gambar 1. Scatterplot PT. Mandom Indonesia (Sumber: Data diolah)

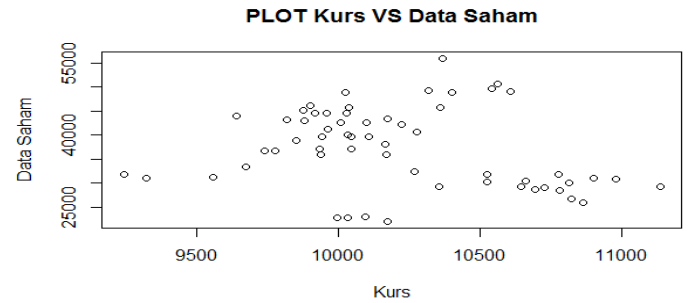

Gambar 2. Scatterplot PT. Unilever Indonesia (Sumber: Data diolah)

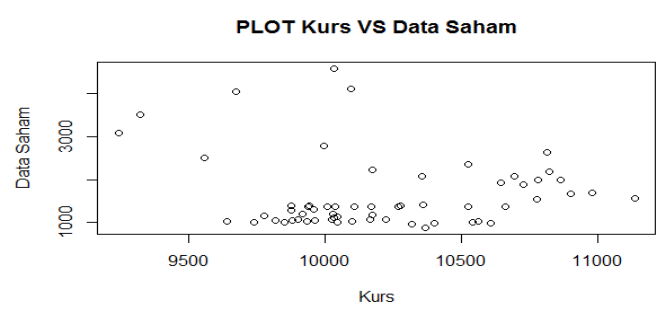

Gambar 3. Scatterplot PT. Akasha Wira Internasional (Sumber: Data diolah)

Dari gambar scatterplot pada masingmasing perusahaan, dapat dilihat bahwa data memiliki pola yang berubah-ubah pada setiap rentang nilai amatan, sehingga pada penelitian ini data nilai kurs terhadap harga saham akan diestimasi menggunakan pen-dekatan regresi nonparametrik.

\section{B. Pemilihan Titik Knot Pada Setiap Perusahaan}

Pemilihan titik knot optimal sangat penting dalam menentukan model regresi nonparametrik terbaik. Titik knot merupakan titik perpaduan bersama dimana terdapat perubahan pola perilaku fungsi atau kurva. Titik knot optimal dapat diperoleh dengan mencari nilai GCV minimum.

Pemilihan nilai GCV minimum dengan melakukan percobaan pada orde terendah yaitu 
orde 2 (model linier) dan jumlah titik knot 1 , lalu dilanjutkan dengan menambahkan orde dan titik knot sampai menghasilkan nilai GCV minimum, jika penambahan orde dan titik knot menghasilkan nilai GCV yang lebih besar maka penambahan orde dan titik knot tidak optimal.

Nilai GCV minimum pada setiap perusahaan dapat dilihat pada Tabel 1.

Tabel 1. Nilai GCV Minimum

\begin{tabular}{|l|c|c|c|c|}
\hline Perusahaan & Orde & $\begin{array}{c}\text { Jumlah } \\
\text { Knot }\end{array}$ & Titik Knot & $\begin{array}{c}\text { Nilai } \\
\text { GCV }\end{array}$ \\
\hline $\begin{array}{l}\text { PT.Mandom } \\
\text { Indonesia } \\
\text { Tbk (TCID) }\end{array}$ & 3 & 3 & $\begin{array}{l}10099,89 ; \\
10316,38 ; \\
10606,31\end{array}$ & 7111340 \\
\hline $\begin{array}{l}\text { PT.Unilever } \\
\begin{array}{l}\text { Indonesia } \\
\text { Tbk } \\
\text { (UNVR) }\end{array}\end{array}$ & 3 & 3 & $\begin{array}{l}10099,8 ; \\
10316,38 ; \\
10606,31\end{array}$ & 55996260 \\
\hline $\begin{array}{l}\text { PT. Akasha } \\
\begin{array}{l}\text { Wira } \\
\text { Internasional } \\
\text { Tbk (ADES) }\end{array}\end{array}$ & 2 & 4 & $\begin{array}{l}9879,97 ; \\
10006,65 ; \\
10099,89 ; \\
10316,38\end{array}$ & 620822 \\
\hline
\end{tabular}

\section{Menentukan Model Spline Truncated Terbaik Pada Setiap Perusahaan}

Model untuk data longitudinal terbaik menggunakan regresi nonparametrik spline truncated diperoleh dengan mencari nilai GCV minimum, setelah diperoleh nilai GCV minimum maka dapat ditentukan estimasi parameter pada setiap perusahaan, dapat dilihat pada Tabel 2.

Tabel 2. Estimasi Parameter

\begin{tabular}{|l|c|l|}
\hline \multicolumn{1}{|c|}{ Perusahaan } & Parameter & \multicolumn{1}{|c|}{$\begin{array}{c}\text { Estimasi } \\
\text { Parameter }\end{array}$} \\
\hline PT. Mandom & $\alpha_{10}$ & $-615668,6$ \\
Indonesia Tbk & $\alpha_{11}$ & 123,6 \\
(TCID) & $\alpha_{12}$ & $-0,006$ \\
& $\beta_{13}$ & 0,028 \\
& $\beta_{14}$ & $-0,073$ \\
& $\beta_{15}$ & 0,086 \\
\hline PT. Unilever & $\alpha_{20}$ & -3409635 \\
Indonesia Tbk & $\alpha_{21}$ & 703,22 \\
(UNVR) & $\alpha_{22}$ & $-0,035$ \\
& $\beta_{23}$ & 0,212 \\
& $\beta_{24}$ & 0,4 \\
& $\beta_{25}$ & 0,341 \\
\hline PT. Akasha & $\alpha_{30}$ & 39319,34 \\
Wira & $\alpha_{31}$ & $-3,87$ \\
International & $\beta_{32}$ & 8,75 \\
Tbk (ADES) & $\beta_{33}$ & $-3,23$ \\
& $\beta_{34}$ & $-4,48$ \\
& $\beta_{35}$ & 3,96 \\
\hline
\end{tabular}

Dari estimasi yang diperoleh pada Tabel 2, maka dapat dibentuk persamaan model regresi nonparametrik spline truncated untuk data longitudinal pada masing-masing perusahaan sebagai berikut:

a) Perusahaan 1 (TCID):

$\hat{f}_{K}(x)=$

$\left(-615668,6+123,6 x-0,006 x^{2} \quad ; x<10099,89\right.$

$2240549,18-441,99 x+0,022 x^{2} \quad ; 10099,89 \leq x<10316,38$ $-5528672,65+1064,18 x-0,051 x^{2} ; 10316,38 \leq x<10606,31$ $4145795,16-760,1 x+0,035 x^{2} \quad ; x \geq 10606,31$

b) Perusahaan 2 (UNVR):

$\hat{f}_{K}(x)=$

$\int-3409635+703,22 x-0,035 x^{2} \quad ; x<10099,89$

$\left\{18216013,39-3479,13 x+0,177 x^{2} ; 10099,89 \leq x<10316,38\right.$ $-24355064,59+4673,97 x-0,22 x^{2} ; 10316,38 \leq x<10606,31$ $14005325,24-2559,53 x+0,012 x^{2} ; x \geq 10606,31$

c) Perusahaan 3 (ADES):

$\hat{f}_{K}(x)=$

$(39319,34-3,87 x$

$-47130,39-4,88 x$

$-14808,91+1,65 x$

$30438,59-2,83 x$

$-10414,27+1,13 x$

; $x<9879,97$

$; 9879,97 \leq x<10006,65$

$10006,65 \leq x<10099,89$

$; 10099,89 \leq x<10316,38$

; $x \geq 10316,38$

\section{Menentukan Nilai MAPE}

Nilai MAPE dapat digunakan untuk mengetahui ketepatan sebuah model yang diperoleh.

Diperoleh nilai MAPE untuk model pada setiap perusahaan dengan menggunakan persamaan 12 sebagai berikut:

1. MAPE untuk $Y_{1}$ (PT. Mandom Indonesia) sebesar $9,62 \%$

2. MAPE untuk $Y_{2}$ (PT. Unilever Indonesia) sebesar $15,61 \%$

3. MAPE untuk $Y_{3}$ (PT. Akasha Wira Internasional) sebesar $48,8 \%$

\section{KESIMPULAN DAN SARAN}

Berdasarkan pembahasan tersebut, dapat disimpulkan bahwa pada perusahaan Mandom Indonesia nilai GCV minimum sebesar 7111340 terletak pada orde 3 dengan 3 jumlah knot yaitu pada titik knot 10099,$89 ; 10316,38 ; 10606,31$. Pada perusahaan Unilever Indonesia nilai GCV minimum sebesar 55996260 terletak pada orde 3 dengan 3 jumlah knot yaitu pada titik knot 10099,89 ; 10316,38 ;

10606,31. Pada perusahaan Akasha Wira Internasional nilai GCV minimum sebesar 620822 terletak pada orde 2 dengan 4 jumlah knot yaitu pada titik knot 9879,97 ;

10006,$65 ; 10099,89 ; 10316,38$.

Nilai MAPE untuk PT. Mandom Indonesia sebesar $9,62 \%<10 \%$ sehingga model yang diperoleh sangat akurat untuk digunakan dalam menduga harga saham pada nilai kurs 10099,89; 
10316,38; dan 10606,31. Nilai MAPE untuk PT. Unilever Indonesia terletak diantara 10\%$20 \%$ sehingga model yang diperoleh baik untuk digunakan dalam menduga harga saham pada nilai kurs 10099,89; 10316,38; dan 10606,31.

Nilai MAPE untuk PT. Akasha Wira Internasional terletak pada $20 \%-50 \%$ sehingga model yang diperoleh cukup untuk digunakan dalam menduga harga saham pada nilai kurs 9879,97; 10006,65; 10099,89;dan 10316,38 .

Pada penelitian ini pendekatan yang digunakan untuk memodelkan nilai kurs terhadap saham pada data longitudinal hanya menggunakan regresi spline truncated, diharapkan pada penelitian selanjutnya menggunakan basis fungsi spline yang lainnya seperti penalized spline.

\section{DAFTAR PUSTAKA}

Agustina dan Sumartio, F. 2014. Analisa FaktorFaktor Yang Mempengaruhi Pergerakan Harga Saham Pada Perusahaan Pertambangan. Jurnal Wira Ekonomi Mikroskil, 4 (1), pp.51-61.

Bank Indonesia, 2018. https://www.bi.go.id/id/moneter/kalkulatorkurs/Default.aspx, Diakses tanggal 24 Oktober 2018.

Budiantara, I N. 2011. Penelitian Bidang Regresi Spline Menuju Terwujudnya Penelitian Statistika Yang Mandiri Dan Berkarakter. Seminar Nasional FMIPA Undiksha. Singaraja.
Chen, R. J. C., Bloomfield, P. dan Cubbage, F. W. 2007. Comparing Forecasting Models in Tourism. Journal of Hospitality \& Tourism Research, 32 (1), pp.03-21.

Eubank, R.L. 1999. Nonparametric Regression and Spline Smoothing. 2nd ed. New York: Marcel Dekker.

Litawati, E.K. dan Budiantara, I N. 2013. Pendekatan Regresi Nonparametrik Spline untuk Pemodelan Laju Pertumbuhan Ekonomi (LPE) di Jawa Timur. Jurnal Sains dan Seni POMITS, 2 (2), pp.123-128.

Muklis, F. 2016. Perkembangan Dan Tantangan Pasar Modal Indonesia. Jurnal Lembaga Keuangan dan Perbankan, 1 (1), pp.64-75.

Suparti, Prahutama, A. dan Santoso, R. 2017.Kajian Pemodelan Spline Untuk Data Longitudinal Sebagai Perkembangan Dari Regresi Nonparametrik. Seminar Nasional Pendidikan, Sains dan Teknologi. FMIPA Universitas Muhammadiyah Semarang.

Toruan, R. L. 2018. Pengujian Hipotesis Simultan Parameter Model Regresi Nonparametrik Spline Truncated Pada Data Longitudinal (Aplikasi pada Data Pertumbuhan Ekonomi Provinsi Papua Tahun 2011-2016). Tesis. Fakultas Matematika, Komputasi, Dan Sains Data. Institut Teknologi Sepuluh Nopember. Surabaya.

Yahoo Finance, 2018. https://finance.yahoo.com. Diakses tanggal 24 Oktober 2018. 